\section{REFERENCES}

Åberg, B. \& Ekdahl, I. (1948). Physiol. Plant. 1, 290.

Bharani, S. P., Shah, Y. S. \& Sreenivasan, A. (1953). Proc. Indian Acad. Sci. B, 87, 33.

Horowitz, H. H. \& King, C. G.(1952). J. biol. Chem. 200, 125.

Horowitz, H. H. \& King, C. G. (1954). J. biol. Chem. 205, 815.

Isherwood, F. A., Chen, Y. T. \& Mapson, L. W. (1954). Biochem. J. 56, 1.

Jackel, S. S., Mosbach, E. H., Burns, J. J. \& King, C. G. (1950). J. biol. Chem. 186, 569.
Jackel, S. S., Mosbach, E. H. \& King, C. G. (1951). Arch. Biochem. Biophys. 81, 442.

Longenecker, H. E., Musulin, R. R., Tully, R. H. \& King, C. G. (1939). J. biol. Chem. 129, 445 .

Mapson, L. W. \& Cruickshank, E. M. (1943). Biochem. J. 41, 197.

Mapson, L. W., Cruickshank, E. M. \& Chen, Y.-T. (1949). Biochem. J. 45, 171.

Nightingale, G. T. (1948). Bot. Rev. 14, 185.

Ray, S. N. (1934). Biochem. J. 28, 996.

Roe, J. H. \& Kuether, C. A. (1943). J. biol. Chem. 147, 399.

\title{
The Estimation of 1-Monoglyceride
}

\author{
By C. M. DOWSE AND J. A. SAUNDERS \\ Department of Physiology, The Medical School, King's College, Newcastle upon Tyne 1
}

(Received 14 September 1955)

Pohle, Mehlenbacher \& Cook (1945) first reported a method for the estimation of 1-monoglyceride (1-MG) based on the oxidation of the vicinal hydroxyl groups of the glycerol part of the molecule by periodic acid. The procedure was modified by Pohle \& Mehlenbacher (1950), who used a chloroform-acetic acid mixture as a medium for the oxidation which was allowed to continue for $20 \mathrm{~min}$. The residual periodate was estimated by adding iodide and titrating with thiosulphate solution.

Kummerow \& Daubert (1950) found that this method indicated the presence of small amounts of 1-MG in various natural fats, but that fatty acid derived from fats also showed an apparent 1-MG content. Mattson, Benedict, Martin \& Beck (1952) recorded values for $1-\mathrm{MG}$ of up to $1.5 \%$ with pure tri- and di-glycerides.

Borgström (1954) found that lead tetraacetate, which has oxidizing properties similar to those of periodic acid, gave erroneous values for 1-MG with samples containing unsaturated fatty acids. He attributed the high values to the reduction of the tetraacetate by partially oxidized double bonds in the unsaturated fatty acids.

We have confirmed the observations of Kummerow \& Daubert (1950), and in addition have found that the apparent 1-MG content increases with the time during which periodic acid is allowed to act, up to $24 \mathrm{hr}$.

We have developed an alternative method for the estimation of 1-MG, based on the fact that oxidative splitting of the vicinal hydroxyl groups of the glycerol part of the molecule yields formaldehyde, whereas oxidation of any double bond (other than a terminal one) in the fatty acid part of the molecule would not give formaldehyde. This principle has been applied to the estimation of adrenocortical steroids by Corcoran \& Page (1948) and Daughaday, Jaffe \& Williams (1948). Our procedure is on a somewhat larger scale than that of Corcoran \& Page (1948), the main points of difference being: (1) the replacement of acetic by propionic acid in the oxidation mixture; (2) the removal of chloroform by aeration under reduced pressure; (3) the use of steam in addition to ordinary distillation to remove the formaldehyde.

\section{EXPERIMENTAL}

\section{Apparatus}

A modified all-glass semi-micro-Kjeldahl apparatus (Fig. 1) is used for distillation of formaldehyde formed. The flask used is of $50 \mathrm{ml}$. capacity.

\section{Reagents}

Periodic acid solution. Periodic acid (0.5 g.) (British Drug Houses Ltd.) dissolved in $10 \mathrm{ml}$. of distilled water is used. The solution is stable for some weeks if kept in the dark.

Each batch of periodic acid is assayed by adding an excess of glycerol ( $>12 \mathrm{mg}$.) to $1 \mathrm{ml}$. of periodic acid solution and standing for $15 \mathrm{~min}$. Dilute acid $(5 \mathrm{ml}$. of $\left.\mathrm{N}-\mathrm{H}_{2} \mathrm{SO}_{4}\right)$ and $\mathrm{KI}$ solution $(5 \mathrm{ml},, 10 \%, \mathrm{w} / \mathrm{v})$ are then added and the $\mathrm{I}_{2}$ liberated is titrated with $0.1 \mathrm{~N}-\mathrm{Na}_{2} \mathrm{~S}_{2} \mathrm{O}_{3}$ solution. The titration is repeated with the glycerol omitted. A difference in titration values of $1 \mathrm{ml}$. of $0.1 \mathrm{~N}-\mathrm{Na}_{2} \mathrm{~S}_{2} \mathrm{O}_{3}$ is equivalent to $9.6 \mathrm{mg}$. of periodic acid.

Propionic acid. Sodium propionate (250 g.) (British Drug Houses Ltd.) is dissolved in $200 \mathrm{ml}$. of water, $20 \mathrm{ml}$. of $2.5 \mathrm{~N}-\mathrm{NaOH}$ added and then $\mathrm{KMnO}_{4}$ solution (about $10 \%, w / v)$ until a purple tinge remains on shaking. The mixture is heated to precipitate oxides of manganese and 
filtered, and water is removed by distillation under reduced pressure. Pure $\mathrm{H}_{2} \mathrm{SO}_{4}$ (about $75 \mathrm{ml}$.) is added cautiously, the mixture being kept cool, until the $\mathrm{pH}$ is 1 . The liquid formed is decanted from the solid $\mathrm{Na}_{2} \mathrm{SO}_{4}$ and distilled with a fractionating column. The liquid distilling at $139-141^{\circ}$ is propionic acid. A considerable amount of acid can be recovered from the $\mathrm{Na}_{2} \mathrm{SO}_{4}$ and the liquid distilling below $139^{\circ}$ by extracting with ether, drying with anhydrous $\mathrm{Na}_{2} \mathrm{SO}_{4}$ and again fractionating. The total yield is $160-170 \mathrm{~g}$. of propionic acid.

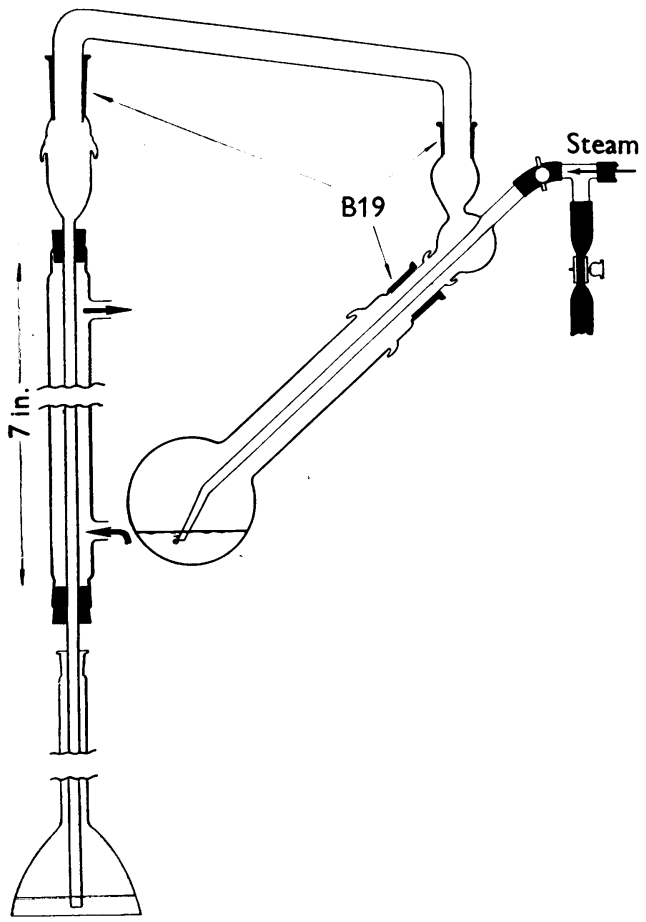

Fig. 1. Apparatus for the oxidation of 1-MG and the distillation of formaldehyde formed.

A $10 \%(v / v)$ solution of propionic acid should give no formaldehyde reaction with chromotropic acid (1:8-dihydroxynaphthalene-3:6-disulphonic acid), and formaldehyde diluted in propionic acid solution should give a reading identical with a similar dilution in water.

Stannous chloride solution. $\mathrm{SnCl}_{2}, 2 \mathrm{H}_{2} \mathrm{O}(6 \mathrm{~g}$.) is dissolved in $\mathrm{N}-\mathrm{HCl}$ to $100 \mathrm{ml}$. The solution is stable for some weeks if kept in the dark with a little granulated tin.

Chromotropic acid. Chromotropic acid (0.1 g.) (British Drug Houses Ltd.) is dissolved in $1 \mathrm{ml}$. of water and made up to $50 \mathrm{ml}$. with $15 \mathrm{M}-\mathrm{H}_{2} \mathrm{SO}_{4}$. Chromotropic acid is kept in the dark and a fresh solution made each day.

Standard formaldehyde solutions. Pure formaldehyde is prepared by the distillation with acid of resublimed hexamethylenetetramine and standardized by determining the amount of $I_{2}$ reduced (MacFadyen, 1945).

\section{Method}

Oxidation of monoglyceride. A sample of fat containing $0.5-2.0 \mathrm{mg}$. of 1-mono-olein is weighed in a stoppered $10 \mathrm{ml}$. flask, $\mathrm{CHCl}_{3}$ added to the mark and the flask weighed again. Samples $(3 \mathrm{ml}$.) from a pipette, calibrated to deliver a known weight of $\mathrm{CHCl}_{3}$, are transferred to a $50 \mathrm{ml}$. dry Kjeldahl flask, $5 \mathrm{ml}$. of propionic acid and $0.05 \mathrm{ml}$. of periodic acid solution are added and mixed by rotation. The flask is allowed to stand for $30 \mathrm{~min}$. The reaction is stopped by the addition of $15 \mathrm{ml}$. of water and $0.5 \mathrm{ml}$. of $\mathrm{SnCl}_{2}$ solution.

Removal of chloroform. The stillhead is inserted and a current of air is drawn through conc. $\mathrm{H}_{2} \mathrm{SO}_{4}$ and soda lime and then through the liquid by means of a suction pump attached to the outlet of the stillhead. By restricting the air inflow the pressure falls until the $\mathrm{CHCl}_{3}$ boils and is drawn into the pump. When all the $\mathrm{CHCl}_{3}$ has been removed the pressure falls to about $10 \mathrm{~cm}$. $\mathrm{Hg}$. The pressure is then allowed to reach atmospheric and the pump disconnected.

Distillation of formaldehyde. A steam generator (with $\mathrm{T}$ outlet) is connected to the stillhead by rubber tubing, closed by means of a screw clip. The outlet from the stillhead is connected to the condenser and a receiving flask (Fig. 1), graduated at $50 \mathrm{ml}$. and containing $5 \mathrm{ml}$. of $0 \cdot 1 \mathrm{~N}-\mathrm{H}_{2} \mathrm{SO}_{4}$, is placed with the delivery tip below the liquid.

The distilling flask is then heated with a micro burner and distillation continued until about $5 \mathrm{ml}$. of liquid remains. The side outlet on the steam generator is closed and the screw clip opened to allow steam to pass through the distilling flask. Direct heating is then discontinued. The receiver is lowered as the distillate increases in volume, so as to keep the delivery tip just below the surface. When the volume of distillate is about $47-48 \mathrm{ml}$. the receiver is lowered and the steam distillation stopped. The distillate is made up to $50 \mathrm{ml}$. and mixed.

Estimation of formaldehyde. A sample of the distillate (3 ml.) is added to $5 \mathrm{ml}$. of chromotropic acid solution in a Pyrex tube, mixed thoroughly and placed in a boilingwater bath for $30 \mathrm{~min}$. After cooling, $2 \mathrm{ml}$. of $9 \mathrm{M}-\mathrm{H}_{2} \mathrm{SO}_{4}$ is added and the contents mixed. The liquid is transferred to a colorimeter tube and read on an EEL colorimeter (Evans Electroselenium Ltd., Harlow, Essex), filter no. 625 being used. A reagent blank and two standard formaldehyde solutions are treated concurrently with each batch of estimations. Five replicates of each solution are treated with chromotropic acid.

\section{RESULTS}

Estimation of formaldehyde. MacFadyen (1945) and Corcoran \& Page (1948) both used a spectrophotometer to measure the colour produced by formaldehyde with chromotropic acid. In the present work it was found that the simpler EEL colorimeter was satisfactory. Six different formaldehyde solutions (range 2.95-14.3 $\mu$ g.), when determined six or more times with each solution, gave a straight line passing through the origin when the readings were plotted against amount of formaldehyde. The slope of the line gave a reading 
of $6 \cdot 53 / \mu \mathrm{g}$. of formaldehyde (range $6 \cdot 43-6 \cdot 65$ for the 6 points).

The standard deviation (s.D.) of 195 determinations of a sample containing $4 \cdot 23 \mu \mathrm{g}$. of formaldehyde was 0.41 , and of 193 determinations of a sample containing $8.46 \mu \mathrm{g}$. of formaldehyde was 0.35 . A reading of 0.41 is equivalent to $0.063 \mu \mathrm{g}$. of formaldehyde and the mean of these replicate determinations will have $95 \%$ confidence limits of $\pm 0.073 \mu \mathrm{g}$. of formaldehyde. This figure is onetwentieth of the corresponding value with Schryver's method for estimating formaldehyde (Dowse \& Saunders, 1955). for 1-MG estimation, and the final readings obtained were compared with those from similar samples which had not been so treated. The results are given in Table 1.

Comparison with the titration method of Pohle \& Mehlenbacher. The amount of material needed for analysis is much less in the present method than in that of Pohle \& Mehlenbacher (1950). The latter needs samples containing $17 \cdot 8 \mathrm{mg}$. of 1 -mono-olein to give a titration difference of $1 \mathrm{ml}$. of $0.1 \mathrm{~N}$ $\mathrm{Na}_{2} \mathrm{~S}_{2} \mathrm{O}_{3}$, whereas the method reported here needs only $1 \mathrm{mg}$. of 1 -mono-olein to give a reading of 33 on the colorimeter, and there is a large amount of

Table 1. Recovery of formaldehyde

\begin{tabular}{cccc} 
Formaldehyde & Colorimeter readings (mean of $5 \pm$ s.D.) & \\
\cline { 2 - 3 }$(\mu \mathrm{g})$ & Untreated & $\begin{array}{c}\text { Treated as for } \\
\text { l-MG determination } \\
\text { (duplicate distillations) }\end{array}$ & $\begin{array}{c}\text { Recovery } \\
(\%)\end{array}$ \\
$49 \cdot 6$ & $19 \cdot 8 \pm 0 \cdot 27$ & $19 \cdot 8 \pm 0 \cdot 27$ & 100 \\
$97 \cdot 8$ & $39 \cdot 0 \pm 0$ & $20 \cdot 1 \pm 0 \cdot 25$ & 101 \\
& & $39 \cdot 1 \pm 0 \cdot 35$ & 100 \\
$120 \cdot 6$ & $48 \cdot 1 \pm 0 \cdot 42$ & $39 \cdot 2 \pm 0 \cdot 27$ & 101 \\
170 & & $47 \cdot 8 \pm 0 \cdot 32$ & 99 \\
195 & $67 \cdot 8 \pm 0 \cdot 84$ & $47 \cdot 7 \pm 0 \cdot 32$ & 99 \\
& & $66 \cdot 8 \pm 0 \cdot 84$ & 99 \\
& $77 \cdot 8 \pm 0 \cdot 84$ & $67 \cdot 0 \pm 1 \cdot 22$ & 99 \\
& & $77 \cdot 8 \pm 0 \cdot 45$ & 100 \\
& & $78 \cdot 0 \pm 0 \cdot 71$ & 100
\end{tabular}

Distillation. Corcoran \& Page (1948) obtained complete recovery of formaldehyde by distilling $10 \mathrm{ml}$. of solution until $1 \mathrm{ml}$. remained. We have found that reducing $20.5 \mathrm{ml}$. to about $4 \mathrm{ml}$. gave uncertain recoveries, but that completing the distillation with steam did give complete recovery. Further steam distillation, continued until a second $50 \mathrm{ml}$. of distillate had been collected, gave no more formaldehyde.

All previous workers have used acetic acid as reaction medium. We found that the samples available to us contained up to $50 \mu \mathrm{g}$. of formaldehyde/ml. This could be diminished to about $0.5 \mu \mathrm{g} . / \mathrm{ml}$. by refluxing with dichromate. The value increased, however, when the acid was stored for a week.

With propionic acid one sample gave no interference with chromotropic acid, whereas others increased or decreased the amount of colour given by formaldehyde. Treatment with permanganate, as described above, uniformly gave samples of propionic acid which neither increased nor decreased the colour given by formaldehyde and chromotropic acid.

\section{Complete method}

Recovery of formaldehyde. Standard solutions of formaldehyde were subjected to the whole process distillate for checking the formaldehyde concentration if necessary.

Twenty-seven different specimens of fat, extracted from the intestinal contents of dogs which had been fed with olive oil, were analysed by both methods. The intestinal contents were acidified with acetic acid, ethanol was added and the fat extracted with ether. The ether was thoroughly washed with water and the acetic acid removed by distillation under reduced pressure in an atmosphere of nitrogen. In all cases the formaldehyde method gave lower values. The range of concentration by the formaldehyde method was $3 \cdot 2-16 \cdot 5 \mathrm{~g}$. of 1-MG/100 g. of fat, the values by the titration method being 2.0-14.4 g./100 g. higher. There was no relationship between the values by the two methods. For example, while one specimen containing $3 \cdot 2 \mathrm{~g}$. of 1-MG/100 g. of fat by the formaldehyde method gave nearly five times as much (15.4 g./100 g.) by the titration method, another sample containing $16.5 \mathrm{~g}$. of $1-\mathrm{MG} / 100 \mathrm{~g}$. of fat gave $19 \cdot 6 \mathrm{~g} . / 100 \mathrm{~g}$. by the titration method.

Table 2 gives some values obtained with fats analysed by the two methods with varying times of oxidation by periodic acid. The figures indicate that with the titration method values obtained with unsaturated fats increase with increasing time of oxidation and that the effect is obtained 
Table 2. Apparent 1-MG content of fats

Method 1, Pohle \& Mehlenbacher (1950). Method 2, this paper.

\begin{tabular}{|c|c|c|c|c|c|c|}
\hline \multirow[b]{2}{*}{ Fat } & \multirow[b]{2}{*}{ Method } & & & & & \\
\hline & & $0 \cdot 17$ & 0.5 & $1 \cdot 0$ & 1.5 & $20-24$ \\
\hline Digested olive oil $A^{*}$ & 1 & $16 \cdot 9$ & $21 \cdot 0$ & - & $26 \cdot 2$ & $(36 \cdot 1) \dagger$ \\
\hline Fatty acid from above & 1 & $0 \cdot 6$ & $4 \cdot 3$ & - & $9 \cdot 0$ & $15 \cdot 1$ \\
\hline Stearic acid (purified) & 1 & $0 \cdot 0$ & 0.0 & - & $0 \cdot 0$ & $0 \cdot 0$ \\
\hline Digested olive oil $B^{*}$ & $\begin{array}{l}1 \\
2\end{array}$ & $\begin{array}{l}7 \cdot 2 \\
3 \cdot 22\end{array}$ & $\begin{array}{l}8.9 \\
4 \cdot 08\end{array}$ & $\begin{array}{l}9 \cdot 8 \\
4 \cdot 03\end{array}$ & $\begin{array}{c}10 \cdot 5 \\
4 \cdot 04\end{array}$ & $=$ \\
\hline Olive oil & $\begin{array}{l}1 \\
2\end{array}$ & $\underline{1.9}$ & $\begin{array}{l}2.5 \\
0.00\end{array}$ & 二 & $\begin{array}{l}3 \cdot 5 \\
0 \cdot 00\end{array}$ & 二 \\
\hline Linseed oil & $\begin{array}{l}1 \\
2\end{array}$ & $\underline{1.6}$ & $\begin{array}{l}1 \cdot 6 \\
0.17\end{array}$ & $\underline{2 \cdot 2}$ & $\begin{array}{l}2 \cdot 8 \\
0 \cdot 17\end{array}$ & $\stackrel{(40 \cdot 0) \dagger}{-}$ \\
\hline Cod-liver oil & $\begin{array}{l}1 \\
2\end{array}$ & $\stackrel{3 \cdot 3}{-}$ & $\begin{array}{l}3 \cdot 3 \\
0 \cdot 15\end{array}$ & $\overline{-}$ & $\begin{array}{l}3.9 \\
0 \cdot 14\end{array}$ & - \\
\hline Commercial 'stearin' & $\begin{array}{l}1 \\
2\end{array}$ & $\begin{array}{c}25 \cdot 6 \\
-\end{array}$ & $\begin{array}{l}30 \cdot 3 \\
28 \cdot 1\end{array}$ & $\begin{array}{l}31 \cdot 5 \\
28.9\end{array}$ & $\begin{array}{l}30 \cdot 9 \\
28 \cdot 8\end{array}$ & - \\
\hline
\end{tabular}

* Digested olive oil means fat which had been extracted from the intestinal contents of dogs which had been fed on olive oil.

$\dagger$ These values indicate that some iodic acid has been reduced, as well as all the periodic acid.

with fatty acid which contains no 1-MG. The present method gives consistent values for unsaturated fats containing 1-MG at oxidation times of 0.5-1.5 hr., and indicates no 1-MG in olive oil and only traces in linseed and cod-liver oils.

\section{DISCUSSION}

We have acted on the hypothesis that the increase in the values for 1-MG obtained by the titration method as the time of oxidation was extended was due to slow reduction of periodic acid by partly oxidized double bonds in the fatty acid part of the molecule, as suggested by Borgström (1954) for his lead tetraacetate method. Our results appear to support this idea, although it is surprising that the titration method gave similar apparent values with olive, linseed and cod-liver oils, whose iodine values are 79-88, 175-202 and 137-166 respectively (International Critical Tables, 1927).

The olive oil fed to the dogs contained no 1-MG according to our method, but $2.5 \mathrm{~g} . / 100 \mathrm{~g}$. according to the titration method. With all the intestinal fat specimens but one, the difference between the values obtained by the two methods was greater than $2.5 \mathrm{~g} . / 100 \mathrm{~g}$. This greater difference is presumably due to double-bond oxidation during the process of extraction.

The commercial stearin sample (Table 2) gave lower values by the formaldehyde method than by the titration method. This may be due to incompletely saturated impurities in the 'stearin'.

\section{SUMMARY}

1. A method for the estimation of 1-monoglyceride, based on the estimation of formaldehyde formed during periodic acid oxidation of 1-monoglyceride, is described.

2. The method eliminates uncertainties which arise in the titration method of Pohle \& Mehlenbacher (1950) when used with unsaturated fats.

This work was done while the authors were in receipt of a grant from the Medical Research Council. We are grateful to Mrs I. Wilkinson for technical assistance.

\section{REFERENCES}

Borgström, B. (1954). Acta physiol. scand. 30, 231.

Corcoran, A. C. \& Page, I. H. (1948). J. Lab. clin. Med. 33, 1326.

Daughaday, W. H., Jaffe, H. \& Williams, R. H. (1948). J. clin. Endocrin. 8, 166.

Dowse, C. M. \& Saunders, J. A. (1955). Biochem. J. 60, xxi.

International Critical Tables (1927). Vol. 2, pp. 201-3. New York: McGraw-Hill.

Kummerow, F. A. \& Daubert, B. F. (1950). J. Amer. Oil Chem. Soc. 29, 261.

MacFadyen, D. A. (1945). J. biol. Chem. 158, 107.

Mattson, F. H., Benedict, J. H., Martin, J. B. \& Beck, E. W. (1952). J. Nutr. 48, 335.

Pohle, W. D. \& Mehlenbacher, V. C. (1950). J. Amer. Oil Chem. Soc. 27, 54.

Pohle, W. D., Mehlenbacher, V. C. \& Cook, J. H. (1945). Oil \& Soap, 22, 115. 